九州大学学術情報リポジトリ

Kyushu University Institutional Repository

Comparative Study on Saikosaponin Contents in Root of Unsexual Propagation and Sexual Reproduction in Bupleurum falcatum

Shon, Tae Kwon

Kyungpook National Unviersity

Park, Soon Ki

Kyungpook National Unviersity

Furuya, Tadahiko

Faculty of Agriculture

Lee, Sang Chul

Kyungpook National Unviersity

https://doi.org/10.5109/4673

出版情報: 九州大学大学院農学研究院紀要. 50 (2)，pp.601-606，2005-10-01. Faculty of Agriculture, Kyushu University

バージョン：

権利関係 : 


\title{
Comparative Study on Saikosaponin Contents in Root of Unsexual Propagation and Sexual Reproduction in Bupleurum falcatum
}

\author{
Tae Kwon SHON ${ }^{1}$, Soon Ki PARK ${ }^{1}$, Tadahiko FURUYA \\ and Sang Chul LEE ${ }^{1 *}$
}

\author{
Laboratory of Crop Science, Division of Agricultural Botany, Department of \\ Plant Resources, Faculty of Agriculture, Kyushu University, \\ Fukuoka 812-8581, Japan \\ (Received June 30, 2005 and accepted July 26, 2005)
}

\begin{abstract}
Production of major constituents in medicinal plants mainly depends on their origin; hence it is possible to produce more of such constituents through selection of potential cultivars. Differences in saikosaponin content and agronomic characteristics between the roots of regenerated plantlets through anther culture and plants cultivated by seed in Bupleurum falcatum were examined. There were significant differences between the means of regenerated plantlet and plant cultivated in fresh weight of aerial part, dry weight of aerial part and dry root length. The saikosaponin contents differed between the different origins. The content of Saikosaponin a in plants with chromosome number $2 n=20$, originated from Korea, was higher than that of $2 n=26$, from Japan, in both regenerated plantlets through anther culture and plants cultivated by seed propagation. But, total saikosaponin contents determined by HPLC were similar between the roots of regenerated plantlets and cultivated plants. Unsexual propagated plants through anther culture have proven to be more homogeneous than those of sexually reproductive plants by seed. To obtain uniform characteristics in B. falcatum, the unsexual propagation through anther culture is one of the effective methods for stable and uniform production in $B$. falcatum.
\end{abstract}

\section{INTRODUCTION}

Recently, demand on production of medicinal plants is increasing especially to supply for crude herbal drugs with elevation of economic development. The demand of Bupleurum falcatum is also extending year by year.

$B$. falcatum shows variation in histological and chemical characteristics in roots of cultivated plants (Shimokawa et al., 1980; Tani et al., 1987; Shon et al., 1997a). Efforts for quality improvement, especially increasing of saikosaponin content in roots, was well studied through cultivation methods, soil ventilation (Hosoda and Noguchi, 1990), cultivation years (Shimokawa and Ohashi, 1980; Park et al., 1992; Sohn et al., 1998) and variety (Shimokawa et al., 1980; Mizukami et al., 1991). The evaluation of plants propagated through somatic embryogenesis of callus culture and cultivated in the field was performed in B. falcatum (Hiraoka et al., 1986), fennel (Miura et al., 1988) and Angelica acutiloba (Nakagawa et al., 1982). But there is no report on the production of saiko-

\footnotetext{
1 College of Agriculture and Life Sciences, Kyungpook National University, 702-701 Daegu, Republic of Korea

* Corresponding author (E-mail: hexa20@hanmail.net)
} 
saponin and its agronomical characteristics in plantlets produced through anther culture and plants propagated by seeds, and as well as varieties of $B$. falcatum. Recently, the anther culture has become widely used as a method for obtaining haploid plants and for shortening the breeding intervals for obtaining high yield and quality of roots in $B$. falcatum. A successful system is thus required for obtaining stable production of major constituents and dry matter.

In this report, to clarify further the production of saikosaponin and its agronomical characteristics, we examined the differences by propagation method using plantlets regenerated through the anther culture and plants propagated by seed to obtain a genetically homogeneous population in two varieties of $B$. falcatum.

\section{MATERIALS AND METHODS}

\section{Plant materials}

B. falcatum, originated from Japan $(2 n=26)$ and Korea $(2 n=20)$, were grown in pots at an experimental field for two years. The cultivation was carried out as described in the following a cultivation method of B. falcatum (Shon et al., 1998). Seeds were distributed from National Crop Experimental Station Suwon, Korea and Tsukuba Medicinal Plant Research Station, National Institute of Health Sciences, Japan. Nine months old plants flowers grown after seeding under natural state were used for anther culture. Production of regenerated plantlets through the anther culture was carried out as described in the method of Shon et al. (1997). Regenerated plantlets and nine months old plants after the transplanting into soil were used for saikosaponin analysis. To investigate the agronomic characteristics such as plant height, stem node, fresh weight, dry weight, root length and xylem ratio, the plants were sampled late November and were dried at natural condition for one week. After drying, it was preserved in tight container for saikosaponin analysis using HPLC.

\section{HPLC analysis}

After alkaline treatment of extract in B. falcatum, saikosaponin a content was determined by high performance liquid chromatography (HPLC) following the modified method of Kimata et al. (1979). Roots sampled from the field were dried at room temperature, and were randomly selected and pulverized using a grinder. Extraction of $500 \mathrm{mg}$ of the powdered $B$. falcatum roots was treated with $10 \mathrm{ml} \mathrm{MeOH}$ containing $0.2 \% \mathrm{KOH}$ at $60^{\circ} \mathrm{C}$ and extracted by ultrasonic apparatus for $3 \mathrm{~min}$. After extraction, the solution was centrifuged with $3000 \mathrm{rpm}$ for $1 \mathrm{~min}$. at $5^{\circ} \mathrm{C}$. After separation of the supernatant, it was extracted twice by same method. This solution was evaporated to dryness at $60^{\circ} \mathrm{C}$. The extracted solution was filled up to $10 \mathrm{ml}$ with $\mathrm{MeOH}$ and filterated by disposable syringe filter of $0.5 \mathrm{~mm}$. $10 \mathrm{ml}$ of solution was subjected to HPLC. The saikosaponin content in the extract was measured by HPLC (LC-10AD, Shimadzu) with a stainless column of TSK-GEL ODS-120A $(4.6 \times 250 \mathrm{~mm}$, TOSOH). The mobile phase was compared to acetonitrile with $50 \mathrm{mM} \mathrm{KH}_{2} \mathrm{PO}_{4}$. The flow rate was $0.5 \mathrm{ml}$ per min and the detection was done at $203 \mathrm{~nm}$. 


\section{RESULTS AND DISCUSSION}

Table 1 shows the means and S.D. values in agronomical and morphological characteristics of $B$. falcatum between plantlets regenerated through the anther culture and plants cultivated by seeding using mean value of two cultivars, originated from Korea $(2 n=20)$ and Japan $(2 n=26)$. There were significant differences between the means of regenerated plantlets and plants cultivated in some factors. The fresh weight of aerial part in sexual reproduction plants was higher than in unsexual propagated plants. Dry weight of aerial part was significant at $5 \%$ level. The unsexual propagated plants showed smaller coefficient variance value than sexual reproduced plants with 1000 -seed weight and root length. Therefore, unsexual propagated plants through the anther culture proved to be more homogeneous than those of sexually reproductive plants by seed. The morphological and agronomical characteristics of the regenerated plantlet were found to be uniform than that of plants cultivated by seed. The general characteristics trend compared among the variables showed higher values in sexual reproduction than unsexual propagation. Hiraoka et al. (1986) reported that the morphological characteristics and secondary metabolite contents of in vitro propagated plants were remarkably uniform as compared with those plants propagated by seeds.

Fig. 1 shows chromatograms of standard saikosaponin by high performance liquid chromatograms at absorbance $251 \mathrm{~nm}$. Retention time was detected as $6.93,10.68,15.10$ min. for saikosaponin c, d, a. The saikosaponin composition were as follow: saikosaponin $\mathrm{d}>$ saikosaponin a $>$ saikosaponin $\mathrm{c}$ in both of cultivars originated from Korea and Japan

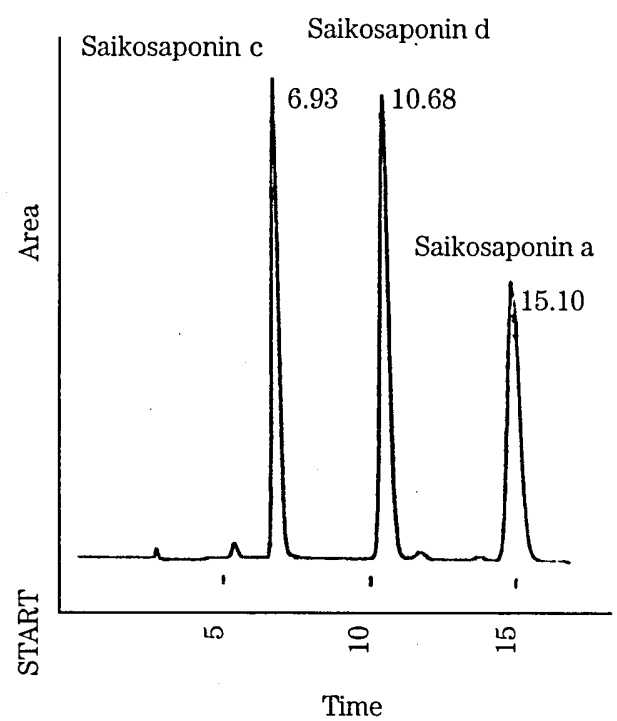

Fig. 1. Chromatograms of standard saikosaponin by HPLC. Detection was performed at $203 \mathrm{~nm}$. 
Table 1. Agronomical and morphological characteristics of B. falcatum plants regenerated through anther culture and seed reproduction.

\begin{tabular}{lrrrrrr}
\hline \multirow{2}{*}{ Variables } & \multicolumn{2}{c}{ Unsexual propagation } & & \multicolumn{2}{c}{ Sexual reproduction } \\
\cline { 2 - 3 } \cline { 5 - 6 } & Mean \pm S.D. & C.V (\%) & & & Mean \pm S.D. & C.V (\%) \\
\hline No, of stem nodes & $20.6 \pm 2.72$ & 17 & & NS & $22.9 \pm 2.88$ & 27 \\
Plant height (cm) & $71.2 \pm 5.49$ & 11 & & NS & $69.5 \pm 4.87$ & 19 \\
Fresh wt. of aerial part (g) & $97.0 \pm 28.3$ & 32 & & $*$ & $112.0 \pm 38.6$ & 45 \\
Dry wt. of aerial part (g) & $34.0 \pm 11.2$ & 21 & & $*$ & $47.0 \pm 12.0$ & 26 \\
Dry root length (cm) & $9.1 \pm 1.32$ & 29 & & $*$ & $10.4 \pm 1.76$ & 22 \\
Dry wt. of root (g) & $1.4 \pm 0.31$ & 26 & & NS & $1.5 \pm 0.42$ & 39 \\
Main root diameter (mm) & $8.2 \pm 0.65$ & 29 & & NS & $8.9 \pm 0.77$ & 37 \\
Xylem ratio (\%) & $62.3 \pm 3.78$ & 37 & & NS & $65.7 \pm 4.43$ & 42 \\
1000-seed weight (g) & $1.64 \pm 0.43$ & 25 & & NS & $1.64 \pm 0.34$ & 18 \\
\hline
\end{tabular}

* Represent significance of the differences between unisexual propagation and sexual reproduction according to Duncan's Multiple Range Test at 5\% level, respectively. NS: no significance. Values represent the mean \pm S.D. from measurement of samples. The xylem tissues which include the inner tissues from cambium, wood fiber, vessel, pith etc.

Table 2. Saikosaponin content in different genetic origins of the root of $B$. falcatum.

\begin{tabular}{|c|c|c|c|c|}
\hline \multirow{2}{*}{$\begin{array}{l}\text { Genetical origin } \\
\text { Saikosaponin contents }\end{array}$} & \multicolumn{2}{|c|}{$2 n=20$} & \multicolumn{2}{|c|}{$2 n=26$} \\
\hline & Mean士S.D & $\mathrm{CV}(\%)$ & Mean士S.D & CV (\%) \\
\hline \multicolumn{5}{|l|}{ Sexual reproduction } \\
\hline Saikosaponin a & $0.632 \pm 0.112$ & 20 & $0.472 \pm 0.093$ & 18 \\
\hline Saikosaponin c & $0.083 \pm 0.028$ & 29 & $0.195 \pm 0.046$ & 23 \\
\hline Saikosaponin d & $0.689 \pm 0.102$ & 14 & $0.734 \pm 0.187$ & 32 \\
\hline Total saikosaponin & $1.334 \pm 0.389$ & 23 & $1.401 \pm 0.338$ & 21 \\
\hline \multicolumn{5}{|l|}{ Unsexual propagation } \\
\hline Saikosaponin a & $0.671 \pm 0.134$ & 17 & $0.513 \pm 0.122$ & 22 \\
\hline Saikosaponin c & $0.123 \pm 0.027$ & 28 & $0.181 \pm 0.031$ & 23 \\
\hline Saikosaponin d & $0.779 \pm 0.134$ & 23 & $0.722 \pm 0.149$ & 18 \\
\hline Total saikosaponin & $1.573 \pm 0.301$ & 20 & $1.416 \pm 0.269$ & 19 \\
\hline
\end{tabular}

Value represents the mean \pm S.D from measurement of nine samples.

(Table 2). This result showed the same as reports of Shon et al. (1997, 1998). Hosoda and Noguchi (1990) also reported that content of saikosaponin in roots was affected by soil ventilation, which was increased by stream or mountainous sand.

Further more, B. falcatum has wide variation in growth, yield, and quality among others. Therefore, genetically uniform cultivars with high yield and quality are urgently needed. From this study, it is revealed that saikosaponin content in the roots is caused by various cultivars. The cultivars originated from Japan $(2 n=26)$ showed higher mean values of saikosaponin production parameters measured than that from Korea $(2 n=20)$ regardless of plant line. This is interpreted to suggest the difference between genotypes for potential crop productivity in B. falcatum. The saikosaponin a content was varied 
between genotypes were $1.334 \%$ for $2 n=20$ and $1.401 \%$ for $2 n=26$ at harvesting stage, which were similar with our previous report (Shon et al., 1998). The cultivars from $2 \mathrm{n}=$ 20 showed higher saikosaponin a content than that from $2 n=26$. This shows that saikosaponin productions are related to genotypes. Therefore, it is proposed that for higher root yield and high saikosaponin production per unit in $B$. falcatum, high root yield of the $2 n=20$ and high saikosaponin content $2 n=26$ must be combined by crossbreeding between the two cultivars. Different genetic origins had not same saikosaponin contents. In case of the saikosaponin content, comparison made in $2 n=20$ showed an increased value than that of $2 n=26$ in sexual reproduction, similar tendency were observed in that of unsexual propagation. Total saikosaponin content showed no differences between the root of unsexual and sexual propagation in the same cultivars at 5\% level of Duncan's Multiple Range Test. Our results showed similar in both of sexual reproduction and unisexual propagation as described by Hiraoka et al. (1986). Also, the results are in agreement with that of Mizukami et al. (1991) and Shimokawa (1980) who showed that saikosaponin contents in the roots plants were observed with different results by their geographical origins.

Saikosaponin contents in $B$. falcatum might be affected by some genetic factors. There were significant differences between the means of regenerated plantlets and plants reproduced by seed in total saikosaponin content. B. falcatum showed variation in morphological, histological and chemical characteristics and growth period. The xylem ratio and saikosaponin content showed differences between bolting and non-bolting roots cultivated in B. falcatum. The non-bolting roots were higher than bolting roots in saikosaponin content (Tani et al., 1987). Kim et al. (1995) reported that saikosaponin contents in adventitious roots formed from callus of $B$. falcatum was differed by growth period, the contents of saikosaponin a and d were the highest at 150 days of culture, whereas the content of saikosaponin $\mathrm{c}$ was the highest at 60 days of culture. Park et al. (1992) determined the differences in cultivation by years, and cultivars in saikosaponin content. The saikosaponin contents of one-year-old roots were higher than those of two year old.

B. falcatum plants, unsexually propagated through the anther culture had uniform in agronomical and morphological characteristics compared to those from sexual reproduction. It could be concluded from this study that obtaining uniform characteristics in B. falcatum, unsexual propagation through anther culture is one of the effective methods for stable and uniform production in B. falcatum.

\section{REFERENCES}

Hiraoka, N., T. Kodama, M. Oyanagi, S. Nakano, Y. Tomita, O. Lida and M. Satake 1986 Characteristics of Bupleurum falcatum plants propagated through somatic embryogenesis of callus cultures. Plant cell Reports, 5: 319-321

Hosoda, K and M. Noguchi 1990 Studies on the cultivation of Bupleurum flcatum L. II. Effect of soil ventilation on the root growth and saponin content. Yakugaku Zasshi, 110: 823-833

Kimata, H., C. Hiyama, S. Yahara, O. Tanaka, O. Ishikawa and M. Aiura 1979 Application of high performance liquid chromatography to the analysis of crude drugs: separatory determination of saponins of Bupleuri Radix. Chem. Pharm. Bull., 27: 1836-1841

Kim, S. G., D. Y. Cho and W. Y. Soh 1995 Saikosponin content in adventitious root formed from callus of Bupleurum falcatum L.. Korean J. Plant Tissue Culture, 22: 29-33 
Miura, Y., H. Fukui and M. Tabata 1988 Reduced inhomogeneity of Angelica acutiloba plants propagated clonally through somatic embryoids. Planta Medica, 54: 79-81

Mizukami, H., K. Matsunaga, H. Ohashi, A. Amano, T. Maekawa and K. Fujimoto 1991 Variation in saikosaponin content of Bupleurum falcatum L. of different geographical origins. Shoyakugaku Zasshi, 45: 342-344

Nakagawa, K., Y. Miura, H. Fukui and M. Tabata 1982 Plant tissue culture. Marugen, Tokyo (Japan), pp. 701-702

Park, Y. J., H. S. Suh, J. W. Shim and S. K. Lee 1992 Comparative saikosaponin determination due to cultivars and root ages in B. falcatum L.. Res. Rept. RDA, 34: 121-124

Shimokawa, Y and H. Ohashi 1980 Cultivation and breeding of Bupleurum falcatum L. (V) Relation among cultivation years, root growth and saikosaponin content. Shoyakugaku Zasshi, 34: 235-238

Shimokawa, Y., I. Okuda, M. Kuwano and H. Ohashi 1980 Cultivation and breeding of Bupleurum falcatum L. (VI) geographical variation of Bupleurum falcatum. Shoyakugaku Zasshi, 34: 239-244

Shon, T. K. and T. Yoshida 1997 Induction of haploid plantlets by anther culture of Bupleurum falcatum L.. Jpn. J. Crop. Sci., 66: 137-138

Shon, T. K., A. D. H. Totok and T. Yoshida 1997a Dry matter production and utilization of solar energy in one-year-old Bupleurum falcatum. J. Fac. Agr. Kyushu Univ., 41: 133-139

Shon, T. K., A. D. H. Totok and T. Yoshida 1997b Variation and distribution of saikosaponin in Bupleurum falcatum L.. J. Fac. Agr. Kyushu Univ., 42: 17-22

Shon, T. K., A. D. H. Totok and T. Yoshida 1998 Studies on dry matter production and efficiency for solar energy utilization in Bupleurum falcatum $\mathrm{L}$. at different plant ages. Plant Production Science, 1: 113-118

Tani, T., T. Katsuki, M. Kubo, Y. Okazaki and S. Arichi 1987 Histological and chemical characteristics of bolting and non-bolting roots of cultivated Bupleurum falcatum L.. Chem. Pharm. Bull., 35: $4530-4536$ 